\title{
Impact of the COronaVIrus Disease 2019 lockdown on hand and upper limb emergencies: experience of a referred university trauma hand centre in Paris, France
}

\author{
Rémy Pichard ${ }^{1,2} \cdot$ Luc Kopel $^{1}$ • Quentin Lejeune ${ }^{3} \cdot$ Rafik Masmoudi $^{3} \cdot$ Emmanuel H. Masmejean $^{1,2,4}$
}

Received: 16 May 2020 / Accepted: 26 May 2020 / Published online: 2 June 2020

(C) SICOT aisbl 2020

\begin{abstract}
Purpose The lockdown imposed in France to cope with the COronaVIrus Disease 2019 (COVID-19) outbreak has led to major changes in the lifestyle of French citizens. The aim of our study was to study its impact on activity related to emergencies in hand and upper limb trauma in comparison to the same reference period in 2019.

Material and methods All consecutive patients consulting for upper limb injury requiring urgent care at Georges-Pompidou European Hospital (HEGP), France, during the lockdown period (case group) and the equivalent period in 2019 (control group) were included. In each group, the type of accident, the anatomical location of the injury, and the treatment were reported and compared. Results Two hundred seventy-five patients were included in the case group in comparison to 784 patients in the control group. We observed a two-third decrease in the rate of upper limb emergencies $(-64.9 \%)$ in particular a drastic drop in the rate of road, work, and leisure accidents $(10.4 \%$ vs $14.3 \%, p=0.1151 ; 10.0 \%$ vs $22.6 \%, p<0.0001 ; 13.1 \%$ vs $30.8 \%, p<0.0001$, respectively), and a clear increase in domestic accidents $(66.5 \%$ vs $32.3 \%, p<0.0001)$. The aetiologies were more dominated by lacerations of soft tissues $(48.4 \%$, vs $38.3 \%, p=0.0034)$ and infections $(8.7 \%$ vs $5.1 \%, p=0.0299)$ with an increase in the indications for surgical management $(51.2 \%$ vs $36.9 \%, p<0.0001)$. Conversely, we observed fewer consultations for joint injuries $(20.7 \%$ vs $30.7 \%, p=0.0015)$ and fractures $(22.2 \%$ vs $25.9 \%, p=0.2210)$.

Conclusion The lockdown imposed in France has changes the etiologies and the management of hand and upper limb emergencies.
\end{abstract}

Keywords COVID-19 $\cdot$ Lockdown $\cdot$ Hand trauma $\cdot$ Hand infection $\cdot$ FESUM

\section{Introduction}

In December 2019, a series of patients with respiratory symptoms suggestive of viral pneumonia emerged in Wuhan, Hubei province, China. On December 21, a diagnostic kit targeting 22 respiratory pathogens returned negative,

Rémy Pichard

rem.pichard@gmail.com; http://www.handsurgery.fr

1 Hand, Upper Limb and Peripheral Nerve Surgery, Georges-Pompidou European Hospital (HEGP), 20 rue Leblanc, 75015 Paris, France

2 University of Paris, Paris, France

3 Emergency Unit, Georges-Pompidou European Hospital (HEGP), Paris, France

4 Clinique Blomet, Research Unit, Paris, France suggesting the presence of a new pathogen previously unknown. SARSCoV2 is identified on January 7, 2020 [1]. In a period of few weeks, the number of COVID-19 (COronaVIrus Disease 2019) patients increased exponentially, first in Asia, then in Europe and the rest of the world, and caused varying degrees of illness [2]. On January 30, The World Health Organization (WHO) declared COVID-19 outbreak a public health emergency of international concern [3] and reclassified it as a pandemic on March 11. [4]. On May 11, we recense 4,091,297 confirmed cases worldwide and 282,104 deaths [5].

In most cases, patients have moderate symptoms, but about $15 \%$ of cases are hospitalized and $5 \%$ require intensive care [6]. In the absence of a COVID-19 vaccine, governments around the world had to take number of public health measures to reduce the transmission of the virus and to avoid a massive influx of patients into public hospitals that could overwhelm health systems [7]. 
As in many countries, the French authorities decided to impose a lockdown period from Tuesday March 17 to Sunday May 10, 2020 to reduce contact rates in the population [8]. As the population is confined, we observe a major decrease in road traffic, workers at risky workplaces, or outdoor leisure activities. Conversely, the risk of domestic accidents and acts of violence seem to increase. These social changes can have an impact on the type of upper extremity injuries requiring emergency room.

In addition, the pandemic has brought about major changes in our medical practices. These are unprecedented in peacetime and more prolonged than those triggered by the terrorist attacks, as on November 13, 2015, in Paris [9]. First, the French government requested hospitals to suspend their nonemergency surgical activity [10]. Secondly, gradually, orthopaedic scientific societies published guidelines specific to orthopaedic surgery during the COVID-19 outbreak and developed protocols for evaluating which operations should be done urgently and which should be delayed [11, 12]. Finally, surgeons have been redeployed in different units to provide medical and paramedical assistance in emergency departments, COVID-19 units, and intensive care units [13]. In Paris hospitals, as in the rest of French territory, the surgical activity has drastically decreased. Over the last two weeks of March, there was $65 \%$ less activity in scheduled orthopaedics [14].

The present study was undertaken to evaluate the impact of the lockdown imposed in France in the context of the COVID19 outbreak on activity related to emergencies in hand and upper limb trauma, in Georges-Pompidou European Hospital (HEGP), SOS Mains HEGP, Paris, France.

\section{Material and methods}

\section{Patients}

All consecutive patients consulting for upper limb injury requiring urgent care at Georges-Pompidou European Hospital (HEGP) during the lockdown period (case group) and the equivalent period in 2019 (control group) were included. HEGP in a university hospital, referred as a trauma centre, including a hand emergency unit (SOS Mains HEGP), was accredited by the FESUM (i.e., European Federation for emergency hand centers) [15], the equivalent of the Hand Trauma Committee at the level of the FESSH.

Patients were considered in three different units: emergency room, hand emergency unit (SOS Mains HEGP), and the recovery room (polytrauma).

The inclusion period for the case group corresponds to the confinement period in France (March 17 to May 10, 2020).

The inclusion period for the control group corresponds to the identical period in 2019 (March 19 to May 12, 2019).

Children under the age of 15 were excluded.

\section{Data collection}

Demographic data, medical history, and clinical and radiological data at presentation were collected.

The upper limb injuries requiring urgent care were divided into four categories: soft tissues lacerations, infections, fractures, and joints injuries (luxation, sprain).

In each group, the type of accident, the anatomical location of the injury, and the treatment were reported and compared.

The location of the injury was defined either by distal involvement (wrist and hand) or by proximal involvement (shoulder, arm, elbow, and forearm).

For all trauma, four categories have been defined: road accident, domestic accident, work-related accident, or accident in everyday life (leisure activity), outside the home.

Three specific mechanisms of injuries have been specified: sport accidents, human or animal bites, and aggressions.

Finally, the type of treatment (conservative or surgical) and the hospitalization procedures (outpatient or conventional hospitalization) were reported.

During the lockdown period, the number of patients treated with COVID-19 infection was reported.

\section{Statistical analyses}

Continuous variables are presented as mean with standard deviation; categorical variables are presented as count (percent). Independent two-sample $t$ test and Chi-square test were used as appropriate to compare groups. Statistical significance was defined as $p<0.05$.

\section{Results}

\section{Demographical data}

During the lockdown period in France, we observed a drastic reduction of consultations for orthopaedic emergency in HEGP, with 784 patients in the control group in comparison to 275 patients in the case group (-64.9\%). The demographical data of each group are reported in Table 1. Patients were significatively older (43.7 vs 40.1 years old, $p=0.0060$ ) in the case group than in the control group, but the sex ratio was similar.

\section{Aetiology of upper limb injuries}

The rate of use of the emergency department for tissue lacerations and infections increased significantly from 38.3 to $48.4 \%(p=0.0034)$ and from 5.1 to $8.7 \%(p=0.0299)$, respectively. Conversely, we observed fewer consultations for joint injuries $(20.7 \%$ vs $30.7 \%, p=0.0015)$ and fractures, although this was not significant (Table 2). The proximal or distal 
Table 1 Demographical data

\begin{tabular}{lccc}
\hline & 2019 & 2020 & $P$ value \\
\hline Age (mean, extreme values) & $40.1(15-94)$ & $43.7(15-90)$ & 0.0060 \\
Women (\%) & $347(44.3 \%)$ & $107(38.9 \%)$ & 0.1229 \\
Right-hand dominant (\%)* & $596(93.6 \%)$ & $221(94.0 \%)$ & 0.8569 \\
Smokers (\%)* & $163(26.3 \%)$ & $72(32.9 \%)$ & 0.0621 \\
Injury right side (\%)* & $397(52.0 \%)$ & $142(52.4 \%)$ & 0.9172 \\
Injury related to a psychiatric disorder & $16(2.0 \%)$ & $8(2.9 \%)$ & 0.4052 \\
\hline
\end{tabular}

Significant value is in italics

*Presence of missing values

nature of the involvement of the upper limb did not change between 2019 and 2020.

For trauma, the rate of road accidents and work and leisure accidents decreased drastically ( $10.4 \%$ vs $14.3 \%, p=0.1151$; $10.0 \%$ vs $22.6 \%, p<0.0001 ; 13.1 \%$ vs $30.8 \%, p<0.0001$, respectively), while the domestic accidents more than doubled (66.5\% in 2020 vs $32.3 \%$ in $2019, p<0.0001)$. In particular, we observed a significant decrease in sports accidents $(4.4 \%$ vs $8.6 \%, p=0.0299$ ), and a trend towards an increase in the rate of aggressions ( $7.2 \%$ vs $4.5 \%$ ), although this was not statistically significant (Table 3 ).

\section{Type of treatment}

During the lockdown period, patients benefited more from surgery $(51.2 \%)$ than from conservative treatment $(48.8 \%)$, which was not the case during the reference period in 2019 (36.9\% and $63.1 \%$, respectively, $p<0.0001$ ). As regard operated patients, the rate of outpatient care decreased in 2020 (62.1\% vs $77.3 \%$ in $2019, p=0.0019)$ (Table 4). Four patients with confirmed COVID-19 infections were treated for trauma to the upper limb and three required surgery.

\section{Discussion}

In France, there is no treatment path dedicated to trauma. Injured patients are referred to the emergency room or are transported to the recovery room for the most serious cases.

Table 2 Type and location of injury

\begin{tabular}{lccc}
\hline & 2019 & 2020 & $P$ value \\
\hline Soft tissues laceration & $300(38.3 \%)$ & $133(48.4 \%)$ & 0.0034 \\
Infections & $40(5.1 \%)$ & $24(8.7 \%)$ & 0.0299 \\
Fractures & $203(25.9 \%)$ & $61(22.2 \%)$ & 0.2210 \\
Joint injuries & $241(30.7 \%)$ & $57(20.7 \%)$ & 0.0015 \\
Proximal involvement & $229(29.5 \%)$ & $71(27.1 \%)$ & 0.3525 \\
Distal involvement & $548(70.5 \%)$ & $197(72.9 \%)$ & 0.3525 \\
\hline
\end{tabular}

Significant values are in italics
Each injured organ is taken care of by a different surgeon [16]. For trauma to the upper limb, FESUM brings together 65 centres in France, four centers in Belgium, and one in Luxembourg, and HEGP is one of them [15].

As the current health crisis was unprecedented, no one was able to predict the consequences of such lockdown on hand and upper extremity emergencies. If many studies have proposed guidelines to adapt the organization of care services to cope with this outbreak, to our knowledge, our study is the first to analyze the impact of containment measures on hand and upper limb emergency aetiologies and management. First, our results highlight a clear change in the aetiologies of injuries, which almost no work-related injuries, less road traffic, and leisure accidents, but a significant increase of the domestic accidents. Many patients occupied themselves to gardening, to handiwork, and cooking. To some extent, these results can be compared to those observed during special events as annual Superbowl in the USA. People are used to stay at home watching the game on TV and preparing home-made dishes like guacamole, temporarily living a very short experimental lockdown. Hand wounds increase with manipulation of avocado pits creating an annual epidemic of "avocado hands" [17].

Also, the lockdown had many psychologic impacts, with more anger accidents and domestic violence. This unprecedented social situation has led to an increase in the level of

Table 3 Aetiologies of injuries

\begin{tabular}{lcrr}
\hline & 2019 & 2020 & $P$ value \\
\hline Aetiologies of injuries & & & \\
Road accidents & $105(14.3 \%)$ & $26(10.4 \%)$ & 0.1151 \\
Work accidents & $166(22.6 \%)$ & $25(10.0 \%)$ & $<0.0001$ \\
Leisure accidents & $227(30.8 \%)$ & $33(13.1 \%)$ & $<0.0001$ \\
Domestic accidents & $238(32.3 \%)$ & $167(66.5 \%)$ & $<0.0001$ \\
Specific mechanisms of injuries & & \\
Sport accidents & $63(8.6 \%)$ & $11(4.4 \%)$ & 0.0299 \\
Aggressions & $33(4.5 \%)$ & $18(7.2 \%)$ & 0.0967 \\
Human and animal bites & $15(2.0 \%)$ & $2(0.8 \%)$ & 0.1918 \\
\hline
\end{tabular}

Significant values are in italics 
Table 4 Type of treatment

\begin{tabular}{lrrr}
\hline & 2019 & \multicolumn{1}{l}{2020} & $P$ value \\
\hline Conservative & $473(63.1 \%)$ & $126(48.8 \%)$ & $<0.0001$ \\
Surgical & $277(36.9 \%)$ & $132(51.2 \%)$ & $<0.0001$ \\
Outpatient & $214(77.3 \%)$ & $82(62.1 \%)$ & 0.0019 \\
In patient & $63(22.7 \%)$ & $50(37.9 \%)$ & 0.0019 \\
\hline
\end{tabular}

Significant values are in italics

stress and anxiety of the entire population, starting with the patients who had to consult the hospital. The mental health effects of the COVID-19 pandemic might be profound [18]. Interventions to address the psychological and social longterm repercussions of the pandemic are required [19].

There is an increase in the rate of surgical management, which is explained by the increase in the rate of soft tissue lacerations and infections, requiring exploration in the operating room, and a decrease in the rate of fractures and joint injuries, which can usually benefit from conservative management by plaster cast. Although the aetiologies are different, the injuries observed during 2020 lockdown remained frequent and did not modify our surgical procedures. Conversely, during the attacks of 2015 or during the strikes of December 2019 in France, the hand surgeons had to operate on hand injuries by bullets or by explosions, much rarer [9].

In addition, our results confirm a considerable decrease in the rate of hand and upper extremity emergencies, divided by three compared to the reference period in 2019, as for many other emergencies. For example, in some countries, the reported number of acute stroke admissions decreased by 50\% [20]. This reduction in activity has enabled a redeployment of surgeon teams to other sectors. Everywhere in the world, different measures have been put in place in response to the COVID-19 pandemic by hand surgeons [21-23]. In our department, the number of inpatient beds decreased from 66 to 19 and the number of operating rooms from five to one. The aim was to preserve valuable equipment, nurses, and staff essential resources to treat the virus [24].

Patient care has been formalized at the hospital level. Upon arrival in the emergency room, suspected or confirmed COVID-19 patients follow a sealed circuit from COVID-19 negative patients [25]. With the limitation of access to operating rooms and anaesthetic support, indications for conservative treatment were pushed to their maximum. Anaesthetic procedures like Wide Awake Local Anaesthesia No Tourniquet (WALANT) have been proposed to continue the care of patients with hand and wrist injuries without an anaesthetic team and crucially without generating aerosolized particles and putting our and our colleagues lives at greater risk [26]. Indeed, as nursing staff, orthopaedic surgeons and anaesthesiologists are among the victims of COVID 19 [27]. The correct application of protection rules is expected to adequately protect health surgeons [28, 29]. Unfortunately, the three patients with confirmed COVID-19 operated in our department were unable to benefit from this technique. Despite the risks involved and the organizational constraints, the patients were managed optimally without reducing the level of quality of care provided.

This crisis occurred in the digital age and has profoundly changed our working habits. In particular, new services such as telehealth, virtual visits, and online tools for post-operative recovery were developed $[30,31]$. These technologies will accompany virtual and augmented reality training and digitalization of meetings in the building of medicine of the future.

\section{Conclusion}

The lockdown imposed in France in the context of COVID-19 outbreak has changes the aetiologies and the management of hand and upper limb emergencies. Despite organizational constrains, the quality of care provided remained a priority. To know the impact of such containment measures is essential to anticipate the needs in hand surgery for possible future similar health crisis. Return to normal activities should take several weeks. Due to this period before summer vacation, a complete return of all activities, in case there is no secondary wave, could be in September, at fall.

\section{Compliance with ethical standards}

Conflict of interest The authors declare that they have no conflict of interest.

Ethical approval This article does not contain any studies with human participants or animals performed by any of the authors.

\section{References}

1. Huang C, Wang Y, Li X et al (2020) Clinical features of patients infected with 2019 novel coronavirus in Wuhan, China. Lancet 395(10223):497-506. https://doi.org/10.1016/S0140-6736(20) 30183-5

2. Guan W-J, Ni Z-Y, Hu Y et al (2020) Clinical characteristics of coronavirus disease 2019 in China. N Engl J Med 382:1708-1720. https://doi.org/10.1056/NEJMoa2002032

3. Statement on the second meeting of the International Health Regulations (2005) Emergency Committee regarding the outbreak of novel coronavirus (2019-nCoV) - 30 January 2020. https:// www.who.int/news-room/detail/30-01-2020-statement-on-thesecond-meeting-of-the-international-health-regulations-(2005)emergency-committee-regarding-the-outbreak-of-novelcoronavirus-(2019-ncov)

4. WHO Director-General's opening remarks at the media briefing on COVID-19 - 11 March 2020. https://www.who.int/dg/speeches/ detail/who-director-general-s-opening-remarks-at-the-mediabriefing-on-covid-19\%2D\%2D-11-march-2020 
5. [dataset] Johns Hopkins University. COVID-19 Dashboard by the Center for Systems Science and Engineering (CSSE): https:// gisanddata.maps.arcgis.com/apps/opsdashboard/index.html\#/ bda7594740fd40299423467b48e9ecf6

6. Wu Z, McGoogan JM (2020) Characteristics of and important lessons from the Coronavirus Disease 2019 (COVID-19) outbreak in China: summary of a report of 72314 cases from the chinese center for disease control and prevention. JAMA 323:1239-1242. https:// doi.org/10.1001/jama.2020.2648

7. Ferguson N, Laydon D, Nedjati Gilani G, et al (2020) Report 9: impact of non-pharmaceutical interventions (NPIs) to reduce COVID19 mortality and healthcare demand. Imperial College London. https://doi.org/10.25561/77482

8. Décret $\mathrm{n}^{\circ} 2020-293$ du 23 mars 2020 prescrivant les mesures générales nécessaires pour faire face à l'épidémie de covid-19 dans le cadre de l'état d'urgence sanitaire

9. Gregory TM, Bihel T, Guigui P et al (2016) Terrorist attacks in Paris: surgical trauma experience in a referral center. Injury 47 : 2122-2126. https://doi.org/10.1016/j.injury.2016.08.014

10. Ministère des solidarités et de la santé (2020) Préparation à la phase épidémique de Covid-19. Établissements de santé Médecine de ville Établissements et services médico-sociaux. Guide Méthodologique

11. Sarac NJ, Sarac BA, Schoenbrunner AR et al (2020) A review of state guidelines for elective orthopaedic procedures during the COVID-19 outbreak. J Bone Joint Surg Am 0(0):1-4. https://doi. org/10.2106/JBJS.20.00510

12. DePhillipo NN, Larson CM, O'Neill OR, LaPrade RF (2020) Guidelines for ambulatory surgery centers for the care of surgically necessary/time-sensitive orthopaedic cases during the COVID-19 pandemic. J Bone Joint Surg Am 0(0):1-4. https://doi.org/10.2106/ JBJS.20.00489

13. Ghogawala Z, Kurpad S, Falavigna A et al (2020) Editorial. COVID-19 and spinal surgery. J Neurosurg Spine:1-3. https:// doi.org/10.3171/2020.4.SPINE20468

14. Batteux F, Marty Chastan C, Cheritel C, Matalon H (2020) Tableau de bord Épidémie Covid-19 - Cellule de crise du 1er avril 2020 Direction APHP

15. FESUM i.e. European Federation for emergency hand centers (fesum.fr)

16. Masmejean EH, Faye A, Alnot JY, Mignon AF (2003) Trauma care systems in France. Injury 34:669-673. https://doi.org/10.1016/ s0020-1383(03)00146-3

17. Farley KX, Aizpuru M, Boden SH, Wagner ER, Gottschalk MB, Daly CA (2019) Avocado-related knife injuries: describing an epidemic of hand injury. Am J Emerg Med. https://doi.org/10.1016/j. ajem.2019.06.051

18. Gunnell D, Appleby L, Arensman E et al (2020) Suicide risk and prevention during the COVID-19 pandemic. Lancet Psychiatry. https://doi.org/10.1016/S2215-0366(20)30171-1
19. Holmes EA, O’Connor RC, Perry VH et al (2020) Multidisciplinary research priorities for the COVID-19 pandemic: a call for action for mental health science. Lancet Psychiatry. https://doi.org/10.1016/ S2215-0366(20)30168-1

20. Markus HS, Brainin M (2020) COVID-19 and stroke - a global world stroke organization perspective. Int J Stroke 0(0):1-4. https://doi.org/10.1177/1747493020923472

21. Ducournau F, Arianni M, Awwad S et al (2020) COVID-19: initial experience of an international group of hand surgeons. Hand Surg Rehabil 39:159-166. https://doi.org/10.1016/j.hansur.2020.04.001

22. Hwee J, Chiew J, Sechachalam S (2020) The impact of coronavirus disease 2019 (COVID-19) on the practice of hand surgery in Singapore. J Hand Surg. https://doi.org/10.1016/j.jhsa.2020.04.023

23. Facchin F, Messana F, Sonda R, Faccio D, Tiengo C, Bassetto F (2020) COVID-19: initial experience of hand surgeons in Northern Italy. Hand Surg Rehabil. https://doi.org/10.1016/j.hansur.2020.04. 007

24. Mauffrey C, Trompeter A (2020) Lead the way or leave the way: leading a Department of Orthopedics through the COVID-19 pandemic. Eur J Orthop Surg Traumatol 30(4):555-557. https://doi. org/10.1007/s00590-020-02670-X

25. Leibner ES, Stokes S, Ahmad D, Legome E (2020) Emergency department COVID management policies: one institution's experience and lessons learned. Emerg Med Pract 22:1

26. BSSH. Wide Awake Hand Surgery Handbook v2

27. Guo X, Wang J, Hu D et al (2020) Survey of COVID-19 disease among orthopaedic surgeons in Wuhan, People's Republic of China. J Bone Joint Surg Am. https://doi.org/10.2106/JBJS.20. 00417

28. Rodrigues-Pinto R, Sousa R, Oliveira A (2020) Preparing to perform trauma and orthopaedic surgery on patients with COVID-19. J Bone Joint Surg Am. https://doi.org/10.2106/JBJS.20.00454

29. Awad ME, Rumley JCL, Vazquez JA, Devine JG (2020) Perioperative considerations in urgent surgical care of suspected and confirmed COVID-19 orthopedic patients: operating rooms protocols and recommendations in the current COVID-19 pandemic. $\mathrm{J}$ Am Acad Orthop Surg. https://doi.org/10.5435/JAAOS-D-2000227

30. Menendez ME, Jawa A, Haas DA, Warner JJP, Codman Shoulder Society (2020) Orthopedic surgery post COVID-19: an opportunity for innovation and transformation. J Shoulder Elb Surg 29:10831086. https://doi.org/10.1016/j.jse.2020.03.024

31. Grandizio LC, Foster BK, Klena JC (2020) Telemedicine in hand and upper-extremity surgery. J Hand Surg Am 45:239-242. https:// doi.org/10.1016/j.jhsa.2019.09.007

Publisher's note Springer Nature remains neutral with regard to jurisdictional claims in published maps and institutional affiliations. 